\title{
A Review. Cystic Fibrosis at Forty-Quo Vadis?
}

\author{
PAMELA B. DAVIS AND PAUL A. DI SANT'AGNESE
}

Pediatric Metabolism Branch, National Institutes of Health, National Institute of Arthritis, Metabolism and Digestive

Diseases, Bethesda, Maryland, USA

Cystic fibrosis (CF) is the most common lethal genetic disease in the United States. In the 40 yr since it was first described in necropsy materials, understanding of the clinical syndrome has advanced, the lives of the patients have been extended, and quality of life improved. While impressive progress has been made, the rate of increase in longevity is slowing, and there remain pressing clinical and therapeutic problems. There are no guidelines or endpoints for therapy of pancreatic insufficiency. Much time, effort, and money are spent on nebulizer therapy and postural drainage, with uncertain documentation of their efficacy (39). The appropriate use of antibiotics is still debated. Advances in understanding the biology of Pseudomonas aeruginosa which might presage its destruction have received much public and scientific attention (8). Though $P$. aeruginosa is clearly a major pathogen in CF patients now, Staphylococcus aureus is generally the predominant organism before repeated courses of anti-Staphylococcal antibiotics. Fatal pulmonary disease can occur in the absence of $P$. aeruginosa, and it is likely that if it were eliminated, another organism would supplant it. It would seem that improved understanding of the biochemistry of $P$. aeruginosa and its mucoid transformation might be less a panacea for $\mathrm{CF}$ pulmonary disease than a clue to the nature of the disordered biochemistry in $\mathrm{CF}$ which predisposes these patients to colonization with mucoid $P$. aeruginosa, which is conspicuously absent in other patients with pulmonary disease (47). Nevertheless, all of these lines of investigation are aimed at improving palliation. Understanding of the basic genetic lesion will be essential for specific therapy, for development of screening tests for heterozygotes, and for prenatal diagnosis.

There is little uncontested in CF research; thus, the touchstone of further investigation must be the clinical syndrome of $\mathrm{CF}$, which is well-described and clearly confirmed by a single discriminating laboratory determination: the sweat test.

Any putative basic defect for $\mathrm{CF}$ must explain generalized involvement of exocrine glands but sparing of other tissues. It must also explain the morphologic normality of these glands before the onset of the disease process and the apparent lack of a specific, abnormal secretory product. It must explain the consistent elevation of sweat sodium and chloride due to a transducible factor in the sweat itself, with apparent morphologic and physiologic normality of the sweat glands. Also, any putative basic defect must be demonstrated to be related to the presence of an abnormal gene, and not to be merely a secondary consequence of disease. Thus, identification of the abnormality in heterozygotes (possibly in attenuated form), inclusion of diseased controls (such as patients with bronchiectasis or pancreatic insufficiency of non-CF origin), and exclusion of drug effects are all critical in biochemical studies aimed at the basic defect in $\mathrm{CF}$.

Previously, we teviewed basic research in CF (16). The present essay is not intended to be an exhaustive summary of CF research since that time, but rather a selective review with liberal editorial comment. In 1976, we concluded that the work done at that time gave no unambiguous direction for future efforts (16). Despite new developments in some areas and steady progress in others, this is still the case. It is still not possible to give a clear answer to the pressing question in $\mathrm{CF}-\mathrm{Quo}$ Vadis? Where are you going?

\section{EXOCRINE GLANDS AND THEIR PRODUCTS}

Because CF is a generalized exocrinopathy, the most direct approach to the problem is to study the exocrine glands. However, the mucus-producing exocrine glands behave quite differently from the serous glands (e.g., eccrine sweat glands and parotid glands).

The serous glands are normal morphologically and physiologically at all times in the course of the disease, except for the increased concentration of sodium, chloride, and potassium in sweat. Sweat calcium is normal, and the concentration of electrolytes in parotid saliva is normal as well.

Conversely, the mucous glands throughout the body such as tracheal mucous glands, pancreas, some salivary glands, Brunner's glands, and others may be affected by the pathologic process morphologically and physiologically. The obstruction of organ passages produces most of the clinical manifestations of CF. However, there is increasing evidence that the mucous glands are normal morphologically before onset of the secondary effects of disease. Infants with CF may have normal pancreatic morphology, (41) and if uninfected may have no hypertrophy of the tracheal mucous glands $(42,46)$. Thus, abnormalities of the secretory products have been sought to explain the subsequent morphologic and pathologic changes.

Although there is a general impression that the physico-chemical behavior of CF secretions is abnormal, attempts to demonstrate this have been unsuccessful (16). Viscosity is clearly increased only in pancreatic secretions. Sputum viscosity does not differ from that of some subjects with other pulmonary diseases (34). Biochemical analysis of CF secretory products has not demonstrated an abnormal mucin. The sulfate content of CF secretions may be increased, but the significance of this observation is still unclear.

Because there is no clear demonstration of abnormal organic secretory products, it has been proposed that abnormalities in the inorganic constituents of the CF secretions, especially calcium, might account for their physico-chemical behavior. Indeed, Gugler et al. (25) demonstrated that a protein from submaxillary saliva could be precipitated by calcium, (25) and Forstner and Forstner (24) showed that the solubility of rat intestinal glycoproteins decreased with increasing calcium concentrations (in the millimolar range.) However, only submaxillary saliva has been consistently shown to have elevated calcium content in CF (15); though even for this secretion some patients' values were in the normal range, and the degree of abnormality seemed to correlate with the degree of local disease (2). For saliva from other glands, seminal plasma, cervical mucus, tracheobronchial secretions, and meconium (except in meconium ileus) there is probably no appreciable difference in calcium content in CF materials compared to appropriate controls (15).

Because both serous and mucous glands are normal morphologically before the secondary effects of disease and because specific abnormal secretory products have never been demonstrated in CF, what about the regulation and control of exocrine secretion? There are formidable technical problems in studying this problem. Postmortem materials have been used to investigate 
the process in isolated parotid cells (37) and tracheal explants (4), but there are obvious problems of availability and the effects of terminal stress in these preparations. Surgical or biopsy specimens which can be obtained from patients who are well in addition to those who are seriously ill have clear advantages.

Boat et al. (4) found no difference in the response to cholinergic agents of explanted tracheal epithelium from $C F$ and non-CF sources. Also nasal epithelium, containing only goblet cells, failed to respond to cholinergic stimuli in either type of samples (3). Neutra et al. (40) similarly found no differences by electron microscopy or autoradiography in regulation of mucous secretion by $C F$ and control samples of rectal mucosa maintained in culture for brief periods. Sweat glands have been studied by micropuncture and other techniques $(36,55)$; the precursor solution in the coil is apparently normal in monovalent ion composition but the sweat contains a "factor", as yet undefined chemically, which prevents sodium reabsorption along either normal or CF gland ducts. On a whole organ physiologic level, Hadorn et al. (26) have shown that even patients who have normal pancreatic enzyme release in response to pancreozymin stimulation have impaired bicarbonate response to secretin. Clearly, the possibilities for studying regulation and control of secretion in these preparations have not yet been exhausted; nevertheless, the difficulty in obtaining isolated secretory cell preparations for detailed biochemical studies is a handicap.

Because of these technical difficulties in getting specimens of exocrine glands for study and because regulatory processes may be conserved from tissue to tissue, investigators have turned to accessible tissues for study of mechanisms of regulation and control. Among other systems, the autonomic nervous system ( $\alpha$ and $\beta$-adrenergic and cholinergic systems) and intracellular calcium relocation have been implicated in control of secretion in various organs. The attempt to use fibroblasts in culture to study $\beta$-adrenergic responses was unsuccessful because of extensive within-line variability $(7,14)$. In leucocytes from patients with $C F$, the response of adenosine $3^{\prime}: 5^{\prime}$ cyclic monophosphate (cAMP) to $\beta$-adrenergic stimulation was significantly reduced compared to healthy controls or patients with bronchiectasis: obligate heterozygotes had mean response which was intermediate (12). More detailed analysis suggests that this deficiency is not related to reduced numbers of $\beta$-adrenergic receptors, to adenylate cyclase itself, or to substrate or cofactor availability but to the coupling between the $\beta$ receptor and adenylate cyclase (13). This defect may be symptomatic of a more generalized membrane dysfunction in CF.

Calcium ion may be critical in regulating secretion; it has been proposed that delivery of calcium to a critical site on the inner surface of the plasma membrane is essential for secretion to occur (19). Recently, several studies on intracellular calcium in CF cells have been conducted. Feigal and Shapiro (23) found that calcium uptake by mitochondria in CF fibroblasts was greatly increased; heterozygotes showed an intermediate increase. Because this is an energy-dependent process, they studied fibroblast oxygen consumption and found that mitochondria from CF homozygotes consumed more $\mathrm{O}_{2}$ than controls, with heterozygous cells intermediate (23). The authors suggested that this organelle might be a suitable focus for further investigation and went on to demonstrate that the $\mathrm{pH}$ optimum for NADH dehydrogenase is different from enzymes derived from normal, $\mathrm{CF}$, and $\mathrm{CF}$ heterozygote fibroblasts (53). Also, CF leucocytes accumulate more calcium than normal cells and calcium accumulation of normal cells can be increased to $C F$ levels by exposure to $C F$ serum (1), raising the question of an ionophore-like effect of CF serum, as had been suggested previously (10). These studies await clear delineation of the mechanisms involved. Another line of studies has recently been reopened. Although previous work indicated that the $\mathrm{Ca}$ ATPase was either normal or had reduced activity in parallel with severity of disease (16), Katz (31) reexamined the question, and found reduced $\mathrm{Ca}$ ATPase activity in erythrocytes of $\mathrm{CF}$ patients and in fibroblasts from CF patients and heterozygotes (32).
Again, the implications of the observations remain to be demonstrated. However, alterations in the intracellular content of calcium or in its compartmentalization could conceivably affect many other cellular functions, including secretion.

\section{FIBROBLASTS}

The skin fibroblast has proven to be a treacherous system in CF. It is said (only partly in jest) that the uncontested finding in CF tissue culture research has simply not been repeated. Many of the contradictory studies were discussed in our previous review (16). Nevertheless, study of the fibroblast is attractive for the following reasons: 1) because $\mathrm{CF}$ is a genetic disease, all cells possess the basic genetic lesion though it may not be expressed; 2) the fibroblast, grown in culture, is remote from the secondary effects of disease and malnutrition; and 3) fibroblastic cells are usually the cell type cultured from amniotic fluid, and are, thus, critical for prenatal diagnosis. However, in vivo in CF the fibroblast is apparently normal, so it is possible that the basic defect is not expressed in this cell (58).

Two observations in fibroblasts have been applied recently to cells cultured from amniotic fluid and therefore bear some comment.

Hosli and coworkers $(27,28)$ have reported that the fibroblasts of most CF homozygotes respond to Tamm-Horsfall glycoprotein (a urinary glycoprotein) in the medium by increased release of alkaline phosphatase. These cells were studied by a highly specialized technique essentially as single cells. This work has been extended to amniotic fluid cells (29). However, Riordan et al. (48) were unable to reproduce this phenomenon in fibroblast macrocultures. Also, although 24 of 24 samples in one blind study were identified correctly by Hosli et al. (30), in a second blind study the identification was no better than chance alone (17). The failures to confirm the original result may reflect technical differences or differences in patient populations under study. Nevertheless, it is clear that this method cannot yet be used in clinical decision making.

Epstein and Breslow have reported that $\mathrm{CF}$ fibroblasts are more resistant to the toxic effects of dexamethasone (21), ouabain (in potassium-free medium) (20), sex steroids (5), dibutyryl cyclic AMP, isoproterenol and theophylline than normal cells (22); fibroblasts from obligate heterozygotes for $\mathrm{CF}$ are intermediate (6). One cell line obtained from the amniotic fluid of a mother who previously had a child with CF and later fibroblasts from the skin of the aborted fetus showed increased resistance similar to homozygotes (6). Further studies are now being undertaken using amniotic fluid cells obtained from pregnancies at risk for CF (6). Until now, no other laboratory has published an attempt to replicate these findings (64). The phenomenon is not explained by differences in protein kinase activity, phosphodiesterase activity, cAMP binding sites, steroid binding sites, or $\mathrm{Na} / \mathrm{K}$ ATPase activity, or its inhibition by ouabain (22).

These two observations illustrate some of the difficulties in $\mathrm{CF}$ research with fibroblasts. First, both of these assays require exacting, specialized techniques; thus, it is difficult for others to either confirm or contradict the original positive findings. Second, although the observations in both instances have been extended to amniotic fluid cells, routine clinical application is premature. Amniotic fluid cells are the ultimate blind sample, and independent histologic or biochemical confirmation of the CF phenotype of an aborted fetus is difficult or impossible, so there is no independent check on the accuracy of a diagnostic test, unless the pregnancy is completed. As pressing as the need for prenatal diagnosis is in $\mathrm{CF}$, it does not justify hasty application of even very promising research findings. Third, both these findings have no obvious relation to the clinical syndrome of CF, which should be a touchstone for research. Fourth, the problem of the probable genetic heterogeneity of $\mathrm{CF}$ arises: Could these observations select only $\mathrm{CF}$ patients of a particular genotype? Inclusion of reference cell lines from a central source in promising studies would amel- 
iorate (but not eliminate) this problem. Also, this strategy would permit different biochemical observations to be made on a single cell line for comparative purposes. Fifth, the art of tissue culture enters the problem. Differences in media, growth conditions, and techniques of subculture or harvest may be critical, or the phenomenon under study may be sensitive to the growth phase of the cells or other variables. Factors such as age in culture certainly are critical especially for $\mathrm{CF}$, because $\mathrm{CF}$ cells age more rapidly in culture than control lines (54). All of these problems make analysis of data from fibroblasts fraught with hazard. Nevertheless, it may be that if we find the right question to ask, the differences between normal and CF cells will be qualitative and identifiable under many diverse culture and growth conditions.

\section{ABNORMALITIES IN PLASMA OR SERUM}

Since 1967 when Spock described a factor in CF serum which inhibited ciliary motility, it has been attractive to many investigators to seek identifiable differences between CF and normal serum or plasma. Presumably this could lead to heterozygote identification and prenatal diagnosis and might give some clues to pathogenesis as well. The history of the CF factor has been checkered with irreproducible results and subjective bioassays. These investigations have been reviewed in some detail previously (16) and it was concluded the limitations in their interpretation were serious. However, because biochemical identification of possibly anomalous small peptides in CF fluids has been undertaken, final judgement on the factor(s) will await these data. The latest entry in this field is the identification of an IgM-associated lectinlike activity of molecular weight 18,000 in the serum of $\mathrm{CF}$ patients and heterozygotes by Lieberman et al. (33). The test for this activity has an objective end point, and preliminary results are promising. However, this should not be considered a clinically useful test until its specificity is demonstrated in blind testing and it is reproduced by other investigators.

Another area which received much publicity is the study of protease-antiprotease interactions in $\mathrm{CF}$ serum. For years, the possibility of a deficiency in arginine esterase activity in CF has been debated, with variable results in different laboratories and with different techniques of measurement $(16,18)$. Recently, two groups of investigators have advanced the hypothesis that arginine esterase activity in $\mathrm{CF}$ serum is reduced because of abnormal interactions of serum proteases with $\alpha_{2}$-macroglobulin $\left(\alpha_{2} \mathrm{M}\right)$ which normally converts them from proteases to peptidases (i.e., their specificity is altered from large substrates to small) $(52,61)$. This might account for the existence of "CF factors" thought to be small peptides. In the normal case, they would be degraded by proteases converted to peptidases by $\alpha_{2} \mathrm{M}$ but in $\mathrm{CF}$, due to abnormal protease-antiprotease interactions, this degradation would not occur. However, abnormalities in $\alpha_{2} \mathrm{M}$ in CF have not been confirmed by other groups $(9,49)$. Also, an alternative explanation for at least some of these observations is available. Romeo et al. (50) found that CF patients and their mothers had a trypsin-binding IgG in their serum. This IgG binds trypsin much more avidly than $\alpha_{2} \mathrm{M}$ and may compete with $\alpha_{2} \mathbf{M}$ for trypsin circulating in CF serum, explaining some of the abnormal binding phenomena and protease activity. However, this does not fully explain abnormalities observed in purified $\alpha_{2} M$ from CF patients (51), and, thus, the full verdict is not yet in on the $\alpha_{2} \mathrm{M}$ story. However, a definite relationship between defective structure or function of $\alpha_{2} \mathrm{M}$ and the phenotype of CF has not been established.

\section{ANIMAL MODEL SYSTEMS}

Because of the difficulties and limitations of working with human materials, practical animal model systems have been sought for CF research. To be useful an animal model system need not display exact concordance with $\mathrm{CF}$, but the similarities and differences should be clearly delineated. If an animal model were genetic, it would be preferable to have it in a multiparous animal which reproduces rapidly, is available in large quantities, and is easy to house and maintain (63). Pivetta and Green (44) have identified and characterized two types of mutant mice, one with exocrine pancreatic insufficiency (epi) and the other with cribriform degeneration of the central nervous system, increased salinity of saliva, and diminished ability to clear aerosolized $S$. aureus from the lungs (cri) (45). These animals may be extremely useful in elucidating pathophysiologic and biochemical aberrations which may be related to CF. This work is being conducted with great care and in parallel with work on pharmacologic models of exocrine disturbances. Martinez and coworkers (43) have systematically demonstrated impressive histologic, physiologic, and biochemical similarities between $C F$ patients and rats treated with high doses of reserpine. Pivetta and coworkers have extended the study to reserpinized mice (56). It is probable that direct cytotoxicity and not the autonomic nervous system effects of reserpine are responsible for the CF-like changes in the animals; nevertheless, the model may be useful in defining the pathophysiology of the disease $(38,56)$. The salivary glands and bronchial mucus secreting tissues of the isoproterenol-treated rat also bear some similarity to CF and may prove useful as well $(35,57)$.

One possible animal model which has received much attention by the lay press is a 6-month-old rhesus monkey at the Yerkes Primate Research Colony which at postmortem examination (3 days after death) had some histologic similarities to CF. Even if the monkey should prove to be a genetically diseased proband (his parents are being rebred now), and if his disease proves to resemble CF very closely, the prolonged single-infant gestations of rhesus monkeys will make it unlikely that large numbers of diseased animals would become available for study in the near future.

The etiology of the monkey's disease is in doubt, however, and there is suspicion that nongenetic factors may have caused his illness. One veterinary pathologist, Dr. Joel Wallach, has concluded that selenium deficiency did cause the monkey's disease, and believes that this is the cause of $C F$ as well (60). However, the evidence for the genetic origin of CF is overwhelming $(16,18)$, and selenium levels in blood and liver of CF patients are in the lower normal range (59).

This controversy illustrates another principle in the animal model field: production of CF-like histology, physiology, or biochemistry in an animal by some mechanism does not imply that $\mathrm{CF}$ in man is produced by the same mechanism. Thus, even if selenium deficiency caused the illness of the rhesus monkey (which is not proven) and even if this illness is closely comparable to $\mathrm{CF}$ (which also is not proven), selenium deficiency cannot be implicated in the pathogenesis of CF without extensive investigation.

So we return to the question, Quo Vadis? Should we study basic secretory processes and hope that a unitary derangement would emerge from advancing knowledge in this area? Should we evaluate the empirical observations which have been made in fibroblasts and in serum, and try to trace them to their roots? Is a fresh approach perhaps possible now? Or might we be dealing with a genetic abnormality which is expressed only briefly during development, programming the organism for self-destruction, then fading into the background of dormant DNA? It is known, for example, that rats treated with reserpine during only a brief critical period of development sustain severe and possibly permanent salivary gland injury and are highly susceptible to pneumonia (11). Uncovering such a basic defect would require detailed knowledge of embryology of exocrine glands, shrewd deductions, and luck. Meanwhile, the patients with this most frequent of lethal genetic errors, and their families, continue to wait.

An attempt was made at a conference sponsored jointly by the National Institutes of Health and the Cystic Fibrosis Foundation (62) to interest scientists whose primary research program is not directed at $C F$ in potential application of their work to pressing problems in CF. An impressive catalog of problems in CF research was developed, but the technical, practical, and theoretical constraints on their solutions were clear as well. Because of the mass of contradictory data in CF research, the conference participants 
felt strongly that future studies in $\mathrm{CF}$ should have sufficient numbers of subjects with appropriate controls (both healthy and diseased), that well done negative studies should be disseminated, that positive studies without adequate numbers, appropriate controls, or up-to-date methodology should be regarded with skepticism, and that more data should be gathered on the normal processes which might be deranged in $\mathrm{CF}$. But fresh ideas and insights must be combined with the above points of sound scholarship in order to solve the enigma of CF.

\section{REFERENCES AND NOTES}

1. Banschbach, M. W., Karem, A. G., Love, P. K., and Hilman, B. C.: Cystic fibrosis serum promotes $\left[{ }^{45} \mathrm{Ca}\right]$ uptake by normal human leukocytes. Biochem. Biophys. Res. Comm., 84: 922 (1978).

2. Blomfield, J., Warton, K. L., and Brown, J. M.: Flow rate and inorganic components of submandibular saliva in cystic fibrosis. Arch. Dis. Child., 48: 267 (1973).

3. Boat, T. F., Kleinerman, J. I., Carlson, D. M., Maloney, W. H. and Matthews, L. H.: Human respiratory tract sections: I. Mucous glycoproteins secreted by cultured nasal polyp epithelium from subjects with allergic rhinitis and with cystic fibrosis. Amer. Rev. Resp. Dis., 110: 428 (1974).

4. Boat, T. F., Cheng, P., and Wood, R. E.: Tracheobronchial mucus secretion in vivo and in vitro by epithelial tissues from cystic fibrosis and control subjects. Mod. Probl. Paediatr., 19: 141 (1977).

5. Breslow, J. L., Epstein, J., Fontaine, J. H.: Dexamethasone-resistant cystic fibrosis fibroblasts show cross-resistance to sex steroids. Cell, 13: 663 (1978).

6. Breslow, J. L., Epstein, J., Fontaine, J. H., and Forbes, G. B.: Enhanced dexamethasone resistance in cystic fibrosis cells: potential use for heterozygote detection and prenatal diagnosis. Science, 201: 180 (1978).

7. Buchwald, M., and Mapleson, J. L.: Adenosine $3^{\prime}: 5^{\prime}$-cyclic monophosphate in fibroblasts from patients with cystic fibrosis and its relationship to secretion. Mod. Probl. Paediatr., 19: 165 (1977).

8. Chan, R., Lam, J., Lam, K., and Costerton, J. W.: The role of mucoid strains of pseudomonas in the etiology of pulmonary infections in cystic fibrosis patients (CF Club Abstracts, Rockville, Md. 1979) p. 3

9. Choy, H., Applegarth, D. A., Davidson, A. G. F., and Wong, L. T. K.: Antiplasmin ( $\alpha_{2}$-macroglobulin) activity of plasma from cystic fibrosis patients. Biochem. Biophys. Res. Commun., 82: 1325 (1978).

10. Conover, J. H., Conod, E. J.: The influences of cystic fibrosis serum and calcium on secretion in the rabbit tracheal mucociliary apparatus. Biochem. Biophys. Res. Commun., 83: 1595 (1978).

11. Cutler, L.: Temporary interruption of adrenergic stimuli during development of the rat submandibular gland: a potential model for cystic fibrosis. In Cystic Fibrosis, A Disease in Search of Ideas. Vol. III. (Model systems, DHEW Publication, NIH, 80-174, 1979).

12. Davis, P. B., Braunstein, M., and Jay, C.: Decreased adenosine $3^{\prime}: 5^{\prime}$ cyclic monophosphate response to isoproterenol in cystic fibrosis leukocytes. Pediatr. Res., 12: 703 (1978).

13. Davis, P. B., and Laundon, S. C.: Adenylate cyclase and $\beta$-adrenergic receptors in lymphocytes from patients with cystic fibrosis. Am. Rev. Resp. Dis. 119: 302 (1979).

14. Davis, P. B., Laundon, S. C., and Ulane, M. M.: Hormone-stimulated cyclic AMP production by skin fibroblasts cultured from healthy persons and patients with cystic fibrosis. Pediatr. Res. (in press).

15. Dearborn, D. G.: Water and electrolytes of exocrine secretions. In: J. A. Mangos and R. C. Talamo: Cystic fibrosis: Projections into the future. (Stratton Intercontinental Medical Book Corp., New York, 1976).

16. di Sant'Agnese, P. A., and Davis, P. B.: Research in cystic fibrosis. N. Engl. J. Med., 295: 481, 534, 597 (1976)

17. di Sant'Agnese, P. A., and Davis, P. B.: Research in cystic fibrosis. Monogr. Paediatr., 10: 66 (1979)

18. di Sant'Agnese, P. A., and Talamo, R. C.: Pathogenesis and physiopathology of cystic fibrosis of the pancreas. N. Engl. J. Med., 277: 1285, 1343, 1399 (1967)

19. Douglas, W. W.: Stimulus-secretion coupling: variations on the theme of calciumactivated exocytosis involving cellular and extracellular sources of calcium. In Respiratory Tract Mucus. (Ciba Foundation Symposium, Elsevier/North Holland, 1978) pp. 61-87.

20. Epstein, J., and Breslow, J. L.: Increased resistance of cystic fibrosis fibroblasts to ouabain toxicity. Proc. Natl. Acad. Sci. U.S.A., 74: 1676 (1977).

21. Epstein, J., Breslow, J. L., and Davidson, R. L.: Increased dexamethasone resistance of cystic fibrosis fibroblasts. Proc. Natl. Acad. Sci. U.S.A., 74: (1977)

22. Epstein, J., Breslow, J. L., Fitzsimmons, M. J., and Vayo, M. M.: Pleiotropic drug resistance in cystic fibrosis fibroblasts: increased resistance to cyclic AMP. Somatic Cell Genetics, 4: 451 (1978).

23. Feigal, R. J., and Shapiro, B. L.: Mitochondrial calcium uptake and oxygen consumption in cystic fibrosis. Nature, 278: 276 (1979).

24. Forstner, J. F., and Forstner, G. G.: Effects of calcium on intestinal mucin: implications for cystic fibrosis. Pediatr. Res., 10:609 (1976).

25. Gugler, E., Pallavicini, J., Swerdlow, H., and di Sant'Agnese, P. A.: The role of calcium in submaxillary saliva of patients with cystic fibrosis. J. Pediatr., 71 585 (1967).

26. Hadorn, B., Johansen, P. G. and Anderson, C. M.: Pancreozymin secretin test of exocrine pancreatic function in cystic fibrosis and the significance of the resul for the pathogenesis of the disease. Canad. Med. Assn. J., 98: 377 (1968).
27. Hosli, P., Erickson, R. P., and Vogt, E.: Prospects for prenatal diagnosis of cystic fibrosis: induction of biochemical abnormalities in fibroblasts from patients with cystic fibrosis by a urinary glycoprotein. Biochem. Biophys. Res. Commun., 73: 209 (1976)

28. Hosli, P., and Vogt, E.: Cystic fibrosis: leakage of lysosomal enzymes and of alkaline phosphatase into the extracellular space. Biochem. Biophys. Res. Comm., 79: 741 (1977).

29. Hosli, P., and Vogt, E.: Reliable detection of cystic fibrosis in skin-derived fibroblast cultures. Hum. Gen., 41: 169 (1977)

30. Hosli, P., Kollberg, H., and Vogt, E.: Reliable diagnosis of the major type of cystic fibrosis with fibroblast cultures. Acta Paediatr. Scand., 67: 617 (1978).

31. Katz, S.: Calcium and sodium transport processes in patients with cystic fibrosis. $\mathrm{I}$. A specific decrease in $\mathrm{Mg}^{2+}$-dependent, $\mathrm{Ca}^{2+}$-adenosine triphosphatase activity in erythrocyte membranes from cystic fibrosis patients. Pediatr. Res., 12: 1033 (1978).

32. Katz, S., and Ansah, T. A.: $\mathrm{Ca}^{2+}$-ATPase activity in membrane preparations of cultured fibroblasts from normal volunteers and from patients with cystic fibrosis. (CF Club Abstracts, Rockville, Md. 1979) p. 49.

33. Lieberman, J., Jakkulis, V., Costea, N.: A new screening test for detection of the cystic fibrosis carrier state. (CF Club Abstracts, Rockville, Md. 1979) p. 7.

34. Lopez-Vidriero, M. T., and Reid, L.: Bronchial mucus in health and disease. Brit. Med. Bull., 34: 63 (1978)

35. Mangos, J. A., McSherry, N. R., Benke, P. J., and Spock, A.: Studies on the pathogenesis of cystic fibrosis: the isoproterenol-treated rat as an experimental model, Proceedings of the Fifth International Cystic Fibrosis Conference, Churchill College, September 22-26, 1969. Edited by D. Lawson. (Cambridge, England, Cystic Fibrosis Research Trust, 1969) pp. 25-24.

36. Mangos, J. A.: Microperfusion study of the sweat gland abnormality in cystic fibrosis. Tex. Rep. Biol Med., 31: 651 (1973)

37. Mangos, J. A.: In vitro studies of secretory cell function in cystic fibrosis. Pediatr. Res., 10: 357 (1976).

38. Martinez, J. R., Quissel, D. O., Wood, D. L., and Giles, M.: Abnormal secretory response to parasympathomimetic and sympathomimetic stimulation from the submaxillary gland of rate treated with reserpine. J. Pharmacol. Exp. Ther. 194: 384 (1975).

39. Murray, J. F.: The ketchup-bottle method. N. Engl. J. Med. 300: 1155 (1979)

40. Neutra, M. R., Grand, R. J., and Trier, J. S.: Glycoprotein synthesis, transport, and secretion by epithelial cells of human rectal mucosa: normal and cystic fibrosis. Lab. Invest., 36: 535 (1977).

41. Oppenheimer, E. H., Esterly, J. R.: Cystic fibrosis of the pancreas. Morphologic findings in infants with and without diagnostic pancreatic lesions. Arch. Pathol., 96: 149 (1973).

42. Oppenheimer, E. H.: Tracheal and bronchial mucous glands and epithelium in infants with cystic fibrosis and controls. (CF Club Abstracts, Rockville, Md. 1978) p. 2.

43. Perlmutter, J., Martinez, J. R., Martinez, A. M., and Cooper, C.: The chronically reserpinized rat as a possible model for cystic fibrosis. Vll. Alterations in the secretory response to cholecystokinin and to secretin from the pancreas in vivo. Pediatr. Res., 12: 188 (1978).

44. Pivetta, O. H., and Green, E. L.: Exocrine pancreatic insufficiency a new recessive mutation in mice. J. Hered., 64: 301 (1973)

45. Pivetta, O. H., Sordelli, D. O., and Labal, M. L.: Pulmonary clearance of Staphylococcus aureus in mutant mice with some hereditary alterations resembling cystic fibrosis. Pediatr. Res., 11: 1133 (1977).

46. Reid, L., and deHaller, R.: The bronchial mucous glands-their hypertrophy and change in intracellular mucus. Mod. Probl. Paediatr., 10: 195 (1967).

47. Reynolds, H. Y., di Sant'Agnese, P. A., and Zierdt, C. H.: Mucoid Pseudomonas aeruginosa a sign of cystic fibrosis in young adults with chronic pulmonary disease? J. Am. Med. Assn., 236: 2190 (1976).

48. Riordan, J. R., Wychik, L., and Buchwald, M.: The induction of alkaline phosphatase in four matched pairs of normal and CF fibroblasts. (CF Club Abstracts, Rockville, Md. 1978) p. 86.

49. Roberts, R. C., Nelles, L. P., Hall, P., and Mischler, E.: Comparison of cystic fibrosis and normal $\alpha_{2}$-macroglobulin physicochemical and primary structure studies. (CF Club Abstracts, 1979) p. 8.

50. Romeo, G., Parsons, M., Bossen, A., Blessing-Moore, J., and Cavalli-Sforza, L. Trypsin-binding IgG in cystic fibrosis. Nature, 274: 909 (1978).

51. Shapira, E., Martin, C. L., and Nadler, H. L.: Comparison between purified $\alpha_{2}$ macroglobulin preparations from normal controls and patients with cystic fibrosis. J. Biol. Chem., 252: 7923 (1977).

52. Shapira, E., Rao, G. J. S., Wessel, H. N., and Nadler, H. L.: Absence of an $\alpha_{2}$ macroglobulin-protease complex in cystic fibrosis. Pediatr. Res., 10: 812 (1976).

53. Shapiro, B. L., Feigal, R. J., and Lam, L. F.: Mitochondrial NADH dehydrogenase in cystic fibrosis. Proc. Natl. Acad. Sci. U.S.A., 76: 2979 (1979).

54. Shapiro, B. L., Lam, L. F. H., and Fast, L. H.: Premature senescence in cultured skin fibroblasts from subjects with cystic fibrosis. Science, 203: 1251 (1979).

55. Schulz, I.: Micropuncture studies of the sweat formation in cystic fibrosis. J. Clin. Invest., 48: 1470 (1969).

56. Sordelli, D. O., Cassino, R. J. J., and Pivetta, O. H.: Animal model for cystic fibrosis. Pulmonary clearance of Staphylococcus aureus in mice treated with reserpine. (CF Club Abstracts, Rockville, Md. 1978) p. 92.

57. Sturgess, J., and Reid, L.: The effect of isoprenaline and pilocarpine on: (a) bronchial mucus-secretory tissue and (b) pancreas, salivary glands, heart, thymus, liver and spleen. Brit. J. Exp. Path., 54: 388 (1973).

58. Tissue Culture Approaches to the Study of Cystic Fibrosis. Cystic Fibrosis Conference Reports Vol. 2, Number 1 (1978).

59. Underwood, B. A., Denning, C. R., and Navab, M.: Polyunsaturated fatty acids 
and tocopherol levels in patients with cystic fibrosis. Ann. N.Y. Acad. Sci., 203: 237 (1972)

60. Wallach, J. D., and Garinaise, B.: Cystic fibrosis a perinatal manifestation of selenium deficiency. 13th Annual Conference on Trace Substances in Environmental Health, June 47, 1979, University of Missouri, Columbia, Missouri.

61. Wilson, G. B., and Fudenberg, H. A.: Studies on cystic fibrosis using isoelectric focusing. II. Demonstration of deficient proteolytic cleavage of $\alpha_{2}$-macroglobulin in cystic fibrosis plasma. Pediatr. Res., 10: 87 (1976).
62. Working Conference on CF, South Padre Island, Texas, March, 1979.

63. Workshop on Model Systems for the study of cystic fibrosis. Cystic Fibrosis, A Disease in Search of Ideas. Vol. III. (Model systems, DHEW Publication, NIH, 80-174, 1979).

64. Since this paper was prepared, Kurz, Perkins, and Buchwald have reported that they are unable to confirm that CF fibroblasts display pleiotropic drug resistance [Kurz, J. B., Perkins, J. P., and Buchwald, M.: Science (in press)]. 